\title{
Un grupo de la elite política decimonónica: los imperialistas*
}

Erika Pani

INSTITUTO MORA

Este texto esboza una biografía colectiva de los hombres que colaboraron en primera línea con el imperio de Maximiliano (1864-1867), e intenta descubrir aquellas experiencias compartidas que los empujaron a colaborar con un régimen monárquico, apoyado por las bayonetas francesas.

$\mathbf{L}$

a historiografía tradicional nos ha legado un retrato poco halagüeño de aquellos mexicanos que colaboraron con el imperio de Maximiliano. De Iglesias a Valadés y de Arrangóiz a Fuentes Mares, los historiadores nos han pintado a los "traidores" que tuvieron el mal tino de servir al "llamado imperio", como un

* Una primera versión de este trabajo se presentó en el coloquio Prestigio, Riqueza y Poder. Las Elites en México. 1821-1940, que se llevó a cabo el 1 y 2 de julio de 1998 en el Instituto Mora. Agradezco los comentarios y sugerencias que me hicieron los demás participantes. grupo de hombres "con corazón de canarios y temple de mariposas". ${ }^{1}$ Los imperialistas de la historia patria se reducen a un grupo de personajes pintorescos y excéntricos, como José Ma. Gutiérrez Estrada, político respetable pero totalmente desconectado de la realidad mexicana; José Manuel Hidalgo, frívolo entre frívolos; o fanáticos desbocados como el padre Francisco Javier Miranda. No obstante, al revisar los nombres de quienes colaboraron con el imperio, esta imagen se resque-

${ }^{1}$ Así los describió Francisco Bulnes, Verda. dero, 1973 , p. 638. 
braja. $^{2}$ Entre los altos funcionarios imperiales se encuentran personajes que se habían destacado sobre la escena pública, ya fuera a nivel regional o nacional, desde la década de 1840 . Además, no se trata solamente -como podría esperarse- de los líderes del Partido Conservador, como Alejandro Arango y Escandón, Teodosio Lares, Ignacio Aguilar y Marocho o Miguel Miramón. Al lado de Maximiliano acudieron también varios adictos al Plan de Ayutla como José López Uraga; diputados al Congreso de 1856 -Pedro Escudero y Echánove, José Ma. Cortés Esparza-; destacados liberales de provincia -Jesús López Portillo, Santiago Vidaurri-; miembros de los gabinetes de Santa Anna -Ignacio Trigueros-, de Ignacio Comonfort y Mariano Arista -Manuel Siliceo, José Urbano Fonseca y José María Lacunza-, y el concuño de Juárez.

De este modo, incluso una mirada rápida sobre las listas de colaboradores del emperador pone de manifiesto que su equipo de gobierno de ninguna manera estuvo conformado exclusivamente por truculentos aventureros extranjeros que ni español hablaban, y tampoco por políticos mexicanos marginales. Salvo contadas excepciones, ${ }^{3}$ durante el imperio tanto la burocracia a todos los niveles como los cuerpos municipales y el cuerpo diplomático estuvieron conformados por mexi-

\footnotetext{
${ }^{2}$ Véase anexo 1.

${ }^{3}$ Rondaban al emperador, por ejemplo, extranjeros como el belga Félix Eloín o el alemán padre Agustín Fischer, cuya influencia es difícil determinar. La cartera de Hacienda estuvo, además, de julio a septiembre de 1866 , en manos del francés $M$. Friant.
}

canos experimentados que, en muchos casos, detentaban cuotas propias de poder y representaban intereses localmente arraigados. Si consideramos que fueron tan sólo " 21 inmaculados" los que siguieron a Juárez en su difícil deambular por las regiones del norte, parecería que, lejos de integrar una comparsa exótica de personajes menores, los imperialistas constituían un grupo bien representativo de la elite política de mediados del siglo XIX.

¿Quiénes eran entonces los imperialistas? ¿Qué los empujó a colaborar con el gobierno de un archiduque aus. triaco, impuesto por las bayonetas francesas? Para responder a estas dos preguntas, pretendemos aquí acercarnos a la experiencia de vida colectiva de los funcionarios civiles de primer nivel -ministros, miembros del Consejo de Estado, comisarios y visitadores imperiales, miembros del Supremo Tribunal de Justicia, y miembros de organismos importantes como la Junta Protectora de Clases Menesterosas, la Administración de Bienes Nacionalizados, la Dirección General de Caminos y Puentes y el Tribunal de Cuentas. ${ }^{4}$ Esperamos que esta instantánea del grupo de hombres que sirvió al imperio permita, por un lado, afinar la visión que tenemos de la clase política decimonónica, ${ }^{5}$ de

${ }^{4}$ Para una lista de los hombres que hemos analizado en este trabajo, véase anexo 1. Además de aquellos que ocuparon los cargos aquí especificados, se han tomado en cuenta, por su importancia, militares como Márquez, Miramón y Mejía, los obispos Labastida y Munguía, y Manuel Payno, aunque fue tan sólo regidor de la ciudad de México.

5 Trabajo al que se han abocado ya González y González, Ronda, 1984; Sinkin, Mexican, 1979, y Stephenson, Origins, 1991. 
su composición socioeconómica y regional, de sus redes y sociabilidades, de sus mecanismos de ascenso social y político, y de sus formas de producción y difusión ideológica. Por otro lado buscaremos, dentro de la biografía colectiva de estos hombres, aquellos elementos que contribuyeron a que algunos promovieran activamente la instauración de un trono en México, y a que otros, ante un hecho consumado, aceptaran colaborar con el joven Habsburgo.

\section{LOS IMPERIALISTAS: HOMBRES NACIDOS EN TIEMPOS "DE LOS GIGANTES Y LAS TARASCAS" 6}

Los imperialistas principales formaron un grupo heterogéneo, de más o menos 100 hombres. La mayoría, 60, había nacido antes de la consumación de la independencia, y más de la mitad de éstos, 36, lo hicieron antes de 1810. Se trataba entonces, para la época del imperio, de hombres maduros, algo mayores que aquellos que compusieron la brillante "pléyade de la reforma". ${ }^{7}$ A la llegada del emperador, oscilaban entre los 44 y los 62 años, y sólo cinco tenían 30 años o menos. Podemos entonces hablar de una colección de elder statesmen que, por razones no sólo ideológicas sino también de edad, participaban por última vez en primera línea de la cosa pública.

Lo más probable es que esta generación no recordara haber gozado o

\footnotetext{
${ }^{6}$ José María Lacunza en Muñoz, Muchachos, 1997, p. 161.

${ }^{7}$ González y González, Ronda, 1984, p. 7.
}

sufrido las realidades de la. era virreinal. Para los imperialistas más añosos -y sobre todo para los más conservadores-, la paz y la prosperidad virreinales eran una referencia obligada para ilustrar las ventajas del sistema monárquico, pero esa época se había transformado en un periodo casi mítico, que pervivía en el imaginario más bien como "una memoria grata, como la de los placeres de la niñez". ${ }^{8}$ Por lo tanto, no representaba un modelo operativo: el ideal político de estos hombres no sería ni la monarquía absoluta, ni la española.

Así, la era virreinal se había convertido en poco más que un recuerdo nebuloso, poco pertinente, a veces aprovechado como recurso retórico. La invasión estadunidense representa en cambio una vivencia mucho más pesada, más trascendente. Muchos imperialistas la sufrieron en carne propia, como una experiencia horriblemente deprimente: por lo menos 20 imperialistas participaron directamente en la guerra, ya fuera como combatientes, ya como miembros del gobierno humillado que firmara el tan vituperado Tratado de Guadalupe-Hidalgo en 1848. Este suceso iba a marcarlos profundamente y explica, en parte, el temor patológico de muchos hacia el vecino del norte. ${ }^{9}$ Vivir en un México ocupa-

\footnotetext{
${ }^{8}$ Ignacio Aguilar y Marocho, "Dictamen..." publicado en Boletín, 1863-1865, t. I, p. 527.

${ }^{9}$ Edmundo O'Gorman analiza las razones de la simpatía de los liberales puros hacia Estados Unidos. O'Gorman, México, 1977. Podría quizá sumarse a éstas que los liberales "de la Reforma" no vivieron la humillación de la guerra de 1846 como to hicieron los liberales moderados. La mayoría de estos últimos, además,
} 
do por tropas estadunidenses -escribía José Fernando Ramírez- equivalía a vivir "sin garantías", y era "iterriblemente espantoso!"10 Después de 1846, muchos futuros imperialistas percibieron a Estados Unidos como una amenaza constante, misma que México sería incapaz de contener por sí solo. Únicamente la garantía de una potencia europea podría detener al peligroso vecino de voraces apetitos. Así, el mismo José Fernando Ramírez, como secretario de Relaciones de Mariano Arista, había considerado urgente poner un dique a la política expansionista estadunidense a través de la presencia europea en México. A esto se debe, en parte, su condescendencia hacia España en el asunto de la deuda externa -en la Convención diplomática de 1851-y su actitud intransigente hacia Estados Unidos en el caso del istmo de Tehuantepec. ${ }^{11}$ Para hombres como éste, la intervención francesa representó la versión extrema de ese "dique" para contener al gigante continental. La presencia del ejército francés era molesta y hasta trágica, pero preferible a la dominación de Estados Unidos. ${ }^{12}$ De mane. ra similar, el diario conservador La Sociedad afirmaba que, aunque esperaba

no fueron acogidos por los estadunidenses durante el exilio que sufrieron de 1853-1855.

${ }^{10}$ Carta de José Fernando Ramírez a Francisco Elorriaga, México, septiembre de 1847, en Benson, UT-Austin, colección Genaro García, Intervención francesa, correspondencia miscelánea, 1846-1867, folder 80 B (2).

${ }^{11}$ González, Anatomia, 1977, p. 216.

${ }^{12}$ Para el antiamericanismo de los políticos mexicanos, véase Hale, "Guerra", 1990; O'Gorman, México, 1977; Pani, "Ventana", 1996, p. 84. que la intervención francesa fuese "transitoria", ésta había venido a salvarnos "de nuestra propia anarquía y de la absorción anglosajona". ${ }^{13}$

\section{PROVINCIANOS EN LA CAPITAL}

Los imperialistas eran, en su mayoría, hombres de provincia: sólo nacieron en la capital 19 de ellos. Se destacan, entre los foráneos, los veracruzanos, diez, y los michoacanos: doce en total, casi todos formados en el seminario de Morelia, alma mater de Aguilar y Marocho, Labastida, Munguía... y Melchor Ocampo. El peso de los michoacanos, que representan además un grupo ideológico homogéneo de tendencia legalista, más bien conservadora y católica, sugiere la importancia que tuvieron, para la formación y reclutamiento de la clase política, las instituciones educativas de provincia, como el seminario de Morelia hasta 1847, el Instituto de Ciencias y Artes de Oaxaca, y el Colegio Carolino de Puebla, entre otros. Estos establecimientos no sólo formaron a los políticos mexicanos cultural e ideológicamente, sino que, sobre todo, los dotaron de una serie de alianzas, de redes sociales y políticas. ${ }^{14}$

No obstante su origen provinciano, casi la mitad de los imperialistas, 49, murieron en la ciudad de México o en

\footnotetext{
13 "La Sociedad. Actualidades", La Sociedad, 25 de abril de 1866.

${ }^{14}$ Para el seminario, véase Arenal, "Estu. dios", 1983. Para la concepción del derecho de los seminaristas, véase Adame, "Derecho", 1983 Para el Instituto de Oaxaca, véase Lempérière, "Formación", 1994.
} 


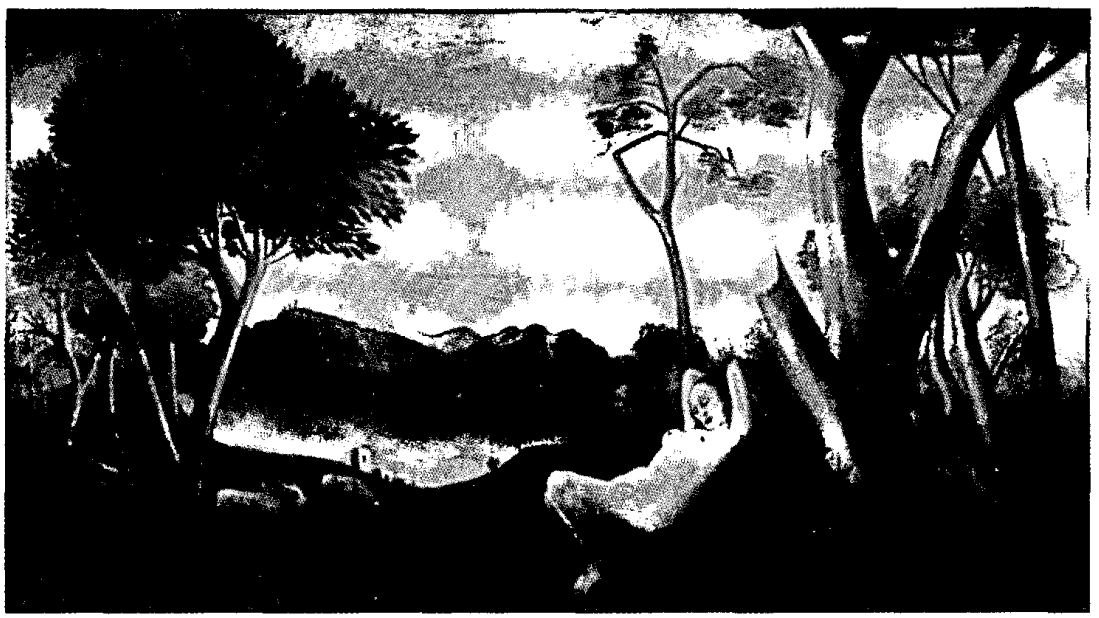

poblados aledaños a la capital -Tacubaya, Azcapotzalco, San Ángel. Esto parece sugerir que, durante la segunda mitad del siglo, México -país en que la mayoría de los hombres notables moría en la capital, y no en su lugar de origen - se iba centralizando cada vez más. Llama la atención, además, que de estos "traidores a la patria", sólo trece -como máximo- morirían en el exilio. Algunos, incluso, antes de morir fueron reciclados por los regímenes posteriores.

En este aspecto no cabe duda de que el caso de Manuel Dublán es excepcional. Casado con la hermana de Margarita Maza de Juárez, ya era diputado en 1869 , y posteriormente fue secretario de Hacienda de 1884 hasta su muerte. No obstante, ni la república restaurada ni el porfiriato quisieron excluir tajantemente a aquellos hombres que, de haberse aplicado riguro- samente la ley del 25 de enero de 1862 , hubieran sufrido cuando menos seis años de presidio, si no es que hubieran sido condenados a muerte. ${ }^{15}$ Por lo menos siete -Escudero y Echánove, Esteva, López Portillo, Luis Méndez, Payno, Pimentel, Roa Bárcena, Salazar Ilarregui- fueron recuperados por instituciones educativas y culturales no completamente desligadas del sector oficial, como el Colegio Militar, la Escuela de Leyes del gobierno de Jalisco, el Colegio Nacional de Abogados, la revista El Renacimiento y el Liceo Hidalgo. El Estado porfirista acudió incluso al rancio conservador Ignacio

${ }^{15}$ Villalpando, Maximiliano, 1997, pp. 22 31. El "contribuir en los puntos ocupados por el invasor a organizar cualquier simulacro de gobierno", representaba un delito en contra de la independencia y seguridad de la nación, aunque la ley no especificaba la pena con que debía castigarse. 
Aguilar y Marocho, miembro fundador de la Sociedad Católica y redactor del diario de oposición La Voz de México, para que formara parte de la comisión que elaboró el Código de la Marina. ${ }^{16}$ Esto, además de atestiguar el notable espíritu conciliador de los vencedores, parece demostrar que la "traición" de los vencidos fue menos aberrante, menos vituperada y menos excepcional de lo que pueden sugerir las descripciones historiográficas. ${ }^{17}$

\section{Profesionistas EN ASCENSO}

Los colaboradores del régimen imperial hicieron, en su gran mayoría, estudios profesionales. En el contexto de la época, pertenecían, claramente, a la elite intelectual y, por tanto, probablemente también a la económica, prácticamente la única que podía costearse estudios superiores. Sin embargo, no se trataba de lo más granado de la sociedad mexicana, sino de profesionistas que antes vivían de su trabajo que de sus rentas. Como ya han apuntado Luis González y González y Fernando Escalante Gonzalbo, la clase política decimonónica provenía de "hogares de medio pelo", de clase media, ${ }^{18}$ y los imperialistas no fueron la excepción. Así, el gobierno de Maximiliano no se conformó, como pudiera pensarse, de rancios y elegantes aristócratas, sino de políticos clasemedieros que habían ascendido la escala del poder político,

\footnotetext{
${ }^{16}$ Aguilar y Marocho, Familia, 1969.

${ }^{17}$ Agradezco los comentarios que me hizo, sobre este punto, el doctor Raúl Figueroa.

${ }^{18}$ González y González, Ronda, 1984, p. 10.
}

no sin dificultad, gracias a su educación, a su desempeño profesional y a sus contactos, cabildeos y palancas... En fin, a la grilla.

Ignacio Aguilar y Marocho, por ejemplo, pudo estudiar en el seminario de Morelia sólo gracias a una beca, y dando clases de español y filosofía a partir del segundo año de carrera. Después de titularse, se pasaría la vida haciendo méritos, primero impartiendo en el seminario las cátedras de derecho civil y canónico, después como socio en un bufete capitalino, como funcionario menor del gobierno de San Luis Potosí -asesor del Tribunal Mercantil, secretario y asesor de gobierno-, finalmente introduciéndose a la vida pública nacional como articulista de El Siglo XIX y de El Universal, como diputado -dos veces-, y dos veces secretario de Estado. Después de tan ajetreada carrera, don Ignacio, sintiéndose quizá amenazado por la entusiasta nueva generación que sobre la ola de la revolución de Ayutla y de elecciones relativamente abiertas había accedido a las curules del Congreso de 1856 , suspiraba en 1863 por un sistema de gobierno que asegurara que la cosa pública estuviera en manos de

esa clase que deriva sus timbres de la fortuna formada por un trabajo honesto, del talento desarrollado por el cultivo, del mérito contraído por hechos extraordinarios $[\ldots]$ que es aristócrata respecto de la democracia del vulgo, y que es democrática en relación con la aristocracia hereditaria. ${ }^{19}$

\footnotetext{
19 "Ignacio Aguilar y Marocho, "Dictamen..." publicado en Boletín, 1863-1865, t. 1, p. 524.
} 
Las vocaciones profesionales de los imperialistas se repartían, según los lineamientos típicos de la época, entre los sectores urbanos medios y altos; 41 de ellos optaron por el derecho -carrera, según Manuel Siliceo, ministro imperial de Instrucción Pública, "preferida por los estudiantes", y cuyos graduados se habían "multiplicado hasta un número muy superior a las necesidades sociales". ${ }^{20}$ En una sociedad pleitista y litigante por tradición, con una economía estancada y desarticulada, la abogacía ofrecía a los hombres de escaso capital propio, cierta seguridad laboral... y, sobre todo, acceso a la administración pública. El aparato gubernativo se convirtió así en fuente privilegiada de ingresos, plazas y contactos para los egresados de los colegios, seminarios e institutos del país. Como atestiguan las largas y variadas carreras políticas de los imperialistas -mismas que analizaremos a continuación-, para muchos de ellos vivir fuera del presupuesto era vivir en el error. Antes que ideólogos, eran políticos de profesión.

De esta forma, por ejemplo, José Serrano, amigo de Ignacio Aguilar y Marocho, para explicar por qué éste permanecía al servicio del imperio tolerando las políticas liberales y secularizantes de Maximiliano, escribía:

[Entendí] que estaba ya en el caso de resolver sin tregua el problema de su porvenir: porque es imposible que usted deje de pensar seriamente en esto. [...] Penetrado de estas reflexiones, supuse que usted estaba predispuesto a

${ }^{20}$ Informe al emperador sobre el estado de la educación, "Parte oficial", El Diario del Imperio, 18 de julio de 1865. aprovechar las ventajas de la nueva era, convirtiendo su influjo en ella al preferente designio de asegurarse una suerte independiente. ${ }^{21}$

Don Ignacio aprovechó sin duda su "influjo" dentro del régimen imperial. Al ratificarse, con ciertas modificaciones, la concesión del ferrocarril México-Veracruz a la Imperial Railway Company, el empresario Antonio Escandón, accionista mayoritario, se mostró lo suficientemente satisfecho con los "buenos servicios" del ministro plenipotenciario del emperador en el Vaticano para recompensarlo con 500 acciones intransferibles de la compañía del ferrocarril, con un rédito de $8 \%$ anual. ${ }^{22}$

No obstante, si bien tanto al gobierno del empérador como al país le sobraban los abogados, éste logró incorporar a su personal un número relativamente importante-sobre todo si se compara con los políticos de la reforma y de la república restaurada- ${ }^{23}$ de políticos de otro tipo, que no provenían del foro, sino de los campos de la ciencia y de la tecnología: nueve imperialistas fueron ingenieros. Según Siliceo, éstos habían emprendido una de las carreras del futuro que el Estado debía promover, pues "tenderían a descubrir y aprovechar nuestros cuantiosos

\footnotetext{
${ }^{21}$ Carta de José Serrano a Ignacio Aguilar y Marocho, México, 23 de abril de 1864, en CONDUMEX, fondo IX-I, carpeta 1 (1850-1864), doc. 50.

${ }^{22}$ Cartas de Antonio Escandón a Ignacio Aguilar y Marocho, París, 7 de agosto de 1864; Biarritz, 15 de septiembre de 1864, en ibid., carpeta 2, docs. 178,197 . El empresario realizó una operación similar en favor de Joaquín Velázquez de León, ministro de Estado.

${ }^{23}$ González y González, Ronda, 1984, anexos.
} 
elementos de riqueza en las primeras materias". ${ }^{24}$ Siguiendo una pauta más tradicional, Maximiliano confió puestos importantes dentro de la administración civil a tres sacerdotes y a quince militares. De estos últimos, todos, con la excepción de Tomás Mejía -cacique indígena- y Ramón Vélez -que de humilde velero pasó a ser oficial del ejército- habían abrazado de manera formal la carrera de las armas. Fueron egresados del Colegio Militar, y algunos, como Bruno Aguilar y José López Uraga, hicieron estudios de especialización en el extranjero. Se trataba, al parecer, más bien de profesionales, de técnicos -ingenieros y matemáticos, académicos- que de fieros jefes militares sin más escuela que el campo de batalla.

\section{CONSTRUCTORES DE LA NACIÓN Y DEL ESTADO}

Como miembros de la elite intelectual, muchos imperialistas pertenecieron a sociedades científicas o culturales, como la Sociedad de Geografía y Estadística y la Academia de San Carlos. Algunos, como Joaquín Velázquez de León, ingeniero, profesor y director de la Escuela de Minería, fueron invitados incluso a ingresar a importantes asociaciones extranjeras, como el Smithsonian Institute de Washington D. C. ${ }^{25}$ Como hombres públicos a la vez que hombres de letras y de ciencia, como miembros de la elite política y cultural de un país prácticamente recién naci-

\footnotetext{
${ }^{24}$ Informe al emperador sobre el estado de la educación, "Parte oficial", El Diario del Imperio, 18 de julio de 1865 .

${ }^{25}$ Ramírez, Biografia, 1885.
}

do, consideraron parte central de su misión el inventar un vínculo emotivo, un sentimiento de identidad que uniera a todos los mexicanos. Así, el forjar una cultura nacional representó uno de sus mayores anhelos. Por ello, muchos de estos hombres participaron en asociaciones literarias como el Ateneo, donde impartió sus Lecciones sobre derecho administrativo Teodosio Lares, o la Academia de San Juan de Letrán, donde discurrieron sobre el carácter de la literatura mexicana futuros rivales políticos como José María Lacunza, Guillermo Prieto y Clemente de Jesús Munguía. Acicateados por preocupaciones similares, siete futuros imperialistas colaboraron en el Diccionario universal de bistoria y geografía (1853-1855), con el que pretendían "levantar un monumento glorioso al país en que vivimos, $[y]$ echar los cimientos de un diccionario histórico exclusivamente mexicano". El propósito de esta obra era describir, catalogar y definir las "cosas mexicanas"; ${ }^{26}$ o sea construir, por lo menos en el papel, a la nación.

Estos profesionistas, juristas, científicos, periodistas y literatos tenían, además, larga experiencia política. Por lo menos quince habían empezado su carrera pública como regidores o síndicos municipales; 29 habían sido miembros del poder legislativo y, de éstos, 16 habían sido representantes del pueblo soberano en dos o más ocasiones; ${ }^{27} 26$ habían sido secretarios o consejeros de Estado; uno había sido el presiden-

${ }^{26}$ Diccionario, 1853-1855, t. I, pp. III-IV.

${ }^{27}$ Ya Cecilia Noriega ha subrayado la estabilidad de la clase política decimonónica. Noriega, "Grupos", 1994, pp. 120-158. 
te más joven de la historia del país; once habían estado al frente del ejecutivo en su estado o departamento; 17 habían sido miembros del poder judicial -estatal o nacional- al más alto nivel; diez habían sido miembros del servicio diplomático. Así, con contadas excepciones -como podría ser el nombramiento del joven e inexperto Francisco Artigas como ministro de Instrucción Pública-, si de algo no podía quejarse el emperador era de que sus colaboradores no conocieran el teje y maneje de la práctica política mexicana.

En cuanto a corrientes ideológicas, si bien pueden identificarse dos grupos, de tendencia más bien liberal moderada uno-principalmente el de quienes fueron miembros del ministerio desde la llegada del emperador hasta septiembre de 1866- y el otro más bien conservador, la filiación política de estos hombres había sido, a lo largo de su carrera, más bien flexible. La vida política del XIX no se prestaba ni a teorías inamovibles ni a posiciones intransigentes. José Fernando Ramírez, por ejemplo, había buscado en 1840 promover una mayor autonomía para los departamentos -en cuanto a la organización de su régimen interior, y a la administración hacendaria y judicial- dentro del marco de la Constitución centralista de $1836 .{ }^{28}$ En 1842 formó parte de la mayoría de la comisión constituyente que rechazó para la república el adjetivo de "federal" que exigía la minoría, pues la "adición de

\footnotetext{
28 "Voto particular del diputado José Fernando Ramírez al proyecto de reformas de las leyes constitucionales", junio 30 de 1840 , en Tena Ramírez, Leyes, 1957, especialmente pp. 287-288.
}

esa palabra [le] pareció impropia y peligrosa". ${ }^{29}$ Como miembro del gabinete, apoyó las políticas anticlericales de Gómez Farías en 1846. Había sido ministro del gobierno "moderado" de Arista, y colaboró con el proyecto de codificación civil de Benito Juárez en 1861. Como ministro imperial, abogó por un Estado nacional fuerte, soberano, libre de las injerencias tanto de los franceses como de la Iglesia.

De manera similar, Teodosio Lares había sido colaborador cercano del gobernador ultrafederalista Manuel González de Cosío. Fue director, entre 1844 y 1847, del Instituto Literario de Zacatecas -institución "liberal" en tanto que ofrecía una alternativa a la formación seminarista, fomentando así la secularización de la educación, su control por parte del Estado y la formación de elites políticas liberales. ${ }^{30}$ Se puede incluso sugerir que, como director del instituto, Lares había promovido una formación profesional relativamente homogénea y centralizada a nivel nacional, pues al solicitar a Mariano Otero que lo asesorara para seleccionar los libros de texto del instituto, le pidió que sus recomendaciones estuvieran acordes con los libros que se utilizaban'en los colegios de la capital. ${ }^{31}$

\footnotetext{
${ }^{29}$ En Tena, Leyes, 1957 , p. 304. No obstante, como ha indicado Cecilia Noriega, el proyecto de la mayoría daba bastantes prerrogativas a los departamentos -administración interior a cargo de asambleas, gobernadores y tribunales designados localmente- y mucha más independencia que la Constitución de 1836. Noriega, Constituyente, 1986, p. 99.

${ }^{30}$ Ríos, "Secularización", 1994 ; Lempérière, "Formación", 1994, especialmente pp. 58-62

${ }^{31}$ Carta de Mariano Otero a Teodosio Lares, México, 1 de mayo de 1844 , en Benson, UT-
} 
Posteriormente, entre 1853 y 1855 , Lares sería el ministro de Justicia de la última dictadura de Santa Anna. La ley de lo contencioso-administrativo (1853) fue quizá la más importante de las medidas por él emprendidas. Al liberar a las acciones del Estado de la injerencia del poder judicial, esta ley lo dotaba de una capacidad de acción mucho más amplia. ${ }^{32}$ Durante el imperio, Lares desempeñaría una actividad febril: como consejero de Estado participó en la reforma del sistema de administración de justicia, del código mercantil y de la ley de lo contencioso-administrativo. Como ministro de Justicia, intentó conciliar los intereses encontrados de la Iglesia y del Estado, buscando la ratifición papal de la nacionalización de los bienes eclesiásticos de 1859 , permitiendo a cambio que la Iglesia pudiera adquirir bienes inmuebles, aunque "el modo y el tiempo de enajenarlos" serían establecidos por el poder civil, de acuerdo con la Santa Sede. ${ }^{33} \mathrm{Al}$ retirarse las tropas francesas y verse perdido el imperio, don Teodosio fue uno de los críticos más acerbos de la abdicación que proponían Maximiliano y el mariscal Bazaine.

De este modo, estos dos imperialistas, como muchos de sus colegas, habían vivido una carrera política ecléctica, plagada de cambios de rumbo y de lealtades. Ramírez decía ser un políti-

Austin, colección Genaro García, núm. 86, Lares papers, folder 1 (1833-1846).

${ }^{32}$ Lira, "Contencioso", 1983.

${ }^{33}$ Carta de Teodosio Lares a Maximiliano, borrador, México, 12 de septiembre de 1866, en Benson, UT-Austin, colección Genaro García núm. 86, Lares papers, folder 8 . co "del justo medio". ${ }^{34}$ La historiografía lo ha descrito como un "republicano de los más rojos"35 -Francisco de Paula y Arrangóiz-; un "moderado fluctuante [...] sabio, vanidoso y sin carácter"36 -Justo Sierra-, o un "conservador" cercano a Aguilar y Marocho y Bernardo Couto ${ }^{37}$-Felipe Tena Ramírez. Asimismo, Teodosio Lares, de liberal decidido, republicano y federalista en los cuarenta, pasó a ser uno de los gallos del liberal moderado Siglo $X I X$ en 1853 por haberse distinguido siempre por "su probidad y su prudencia y las relaciones que [tenía] en todo el país", ${ }^{38}$ para ser condenado por los autores franceses del Libro secreto de Maximiliano como el "instrumento ciego" de la reacción. ${ }^{39}$

No obstante lo sorprendentes que pueden parecer estos bandazos, ninguno de estos hombres recorrió un camino ajeno a la mayoría de los hombres públicos mexicanos de la primera

34 "Voto particular del diputado José Fernando Ramírez al proyecto de reformas de las leyes constitucionales", junio 30 de 1840 , en Tena, Leyes, 1957, p. 295.

${ }^{35}$ Arrangóiz, México, 1968 , p. 589.

${ }^{36}$ Sierra, Juárez, 1970, p. 335.

37 Tena, Leyes, 1957, p. 304.

38 "El nuevo gobierno y la revolución", $E l$ Siglo XIX, 10 de enero de 1853.

${ }^{39}$ En opinión de Lares, era importante que se restableciera la armonía entre la Iglesia y el Estado mexicano, pero el posible concordato debía obedecer a los intereses de la potestad civil -incluyendo aquellos creados por la desamortización- y sostener la autoridad estatal. Carta de Teodosio Lares a Maximiliano, México, 12 de septiembre de 1866, en Benson, UT-Austin, colección Genaro García, núm. 86, Lares papers, folder 8 (1865-1867). Para la opinión de los franceses, véase El libro, 1963, p. 59. 
época independiente. $Y$ si bien se ha condenado a los políticos decimonónicos por chaqueteros, ${ }^{40}$ la agitada carrera política de estos dos hombres pone de manifiesto que, aunque no fueron muy consistentes en cuanto a sus adhesiones, sí lo fueron en lo que toca a su proyecto político, que se mantendría, con ciertas modificaciones, en medio de azarosas circunstancias: el constituir al país "de una manera sólida y estable", como escribía Ramírez ${ }^{41}$ y construir un Estado nacional fuerte y activo, "moderno" en el sentido que le da Max Weber, o sea monopolizador de todos los recursos "políticamente utilizables", como la violencia legítima, la fiscalización, el derecho y la producción de normas, la educación...

De esta forma, los datos biográficos aquí presentados nos pintan un retrato valioso del personal imperial. En. él aparece un grupo de hombres algo mayores, profesionales y cultos. Cuando llegó Maximiliano a la capital, prácticamente todos habían tenido expe-

\footnotetext{
${ }^{40}$ Como escribe Josefina Z. Vázquez, se ha descrito a Antonio López de Santa Anna como "el prototipo del chaquetero que de monárquico e iturbidista pasa a republicano, federalista, centralista, dictador, federalista y promonarquista de nuevo", olvidando que esta plasticidad la compartían muchos de los políticos de la época, como "el prócer liberal, don Valentín Gómez Farías, que también fue monarquista e iturbidista [...] federalista, escocés y hombre de progreso". Citado en Fowler, "Pensamiento", 1997, pp. 4-5.

41 "Voto particular del diputado José Fernando Ramírez al proyecto de reformas de las leyes constitucionales", junio 30 de 1840 , en Tena, Leyes, 1957, p. 287.
}

riencia de gobierno, y ésta había sido, en muchos casos, multifacética. Durante las primeras décadas del México independiente, la participación en la vida pública significaba una experiencia más bien amarga. Como legisladores, como ministros, como militares, como jurisconsultos, estos hombres habían intentado consolidar un Estado-nación moderno. Invariablemente, su ideal se les había desmoronado en las manos. Lo habían intentado todo: primero, un imperio, con el "Consumador de la Independencia" al frente. Después, la república se había ensayado -como escribió José Ma. Gutiérrez de Estrada"democrática, oligárquica, militar, demagógica y anárquica, siempre en detrimento de la felicidad y el honor del país". 42 También la dictadura santanista había dejado mucho que desear. La Constitución de 1857 aunque se había convertido en la bandera de un sector del grupo liberal, tampoco convencía a muchos, y menos a los que habían gobernado con ella. Así, de decepción en decepción, estos hombres habían ido ajustando sus ideologías y sus proyectos político y social a las circunstancias imperantes. Finalmente, en 1864 aceptaron apoyar a un archiduque güero y de ojo azul en su anhelo por construir un imperio mexicano porque vieron en este régimen insólito -pero cuyo referente europeo, el imperio de Napoleón III, era bastante atractivo- la oportunidad de construir aquel Estado sólido por el que tanto suspiraban.

${ }^{42}$ Documentos, 1981, p. 68. 


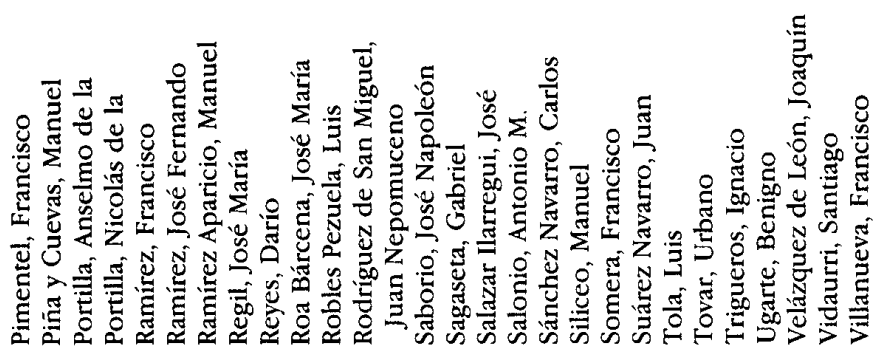

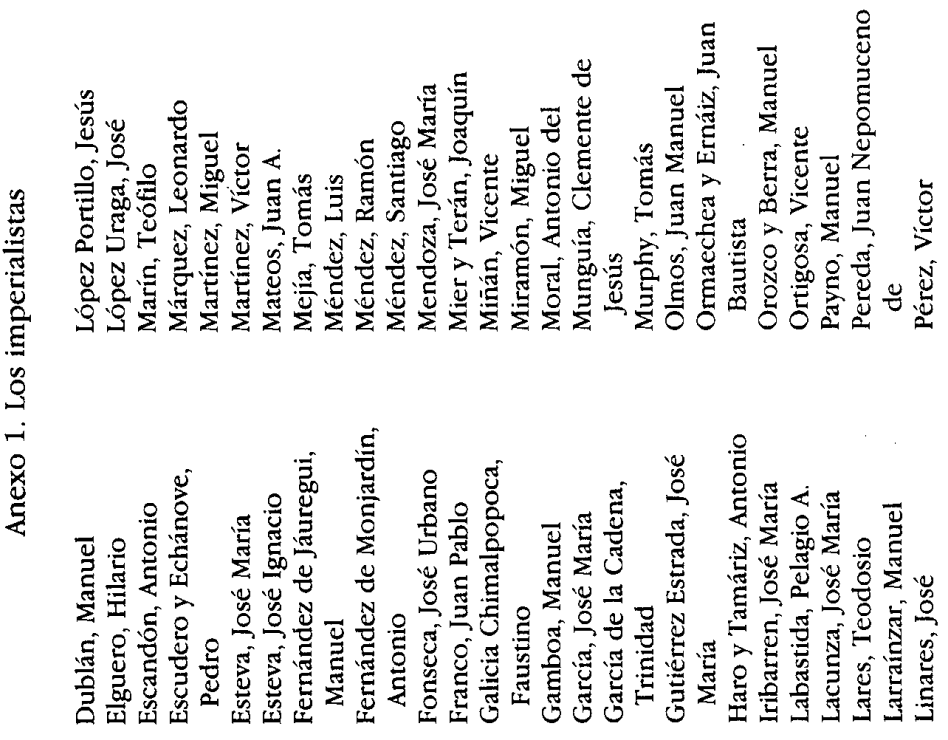

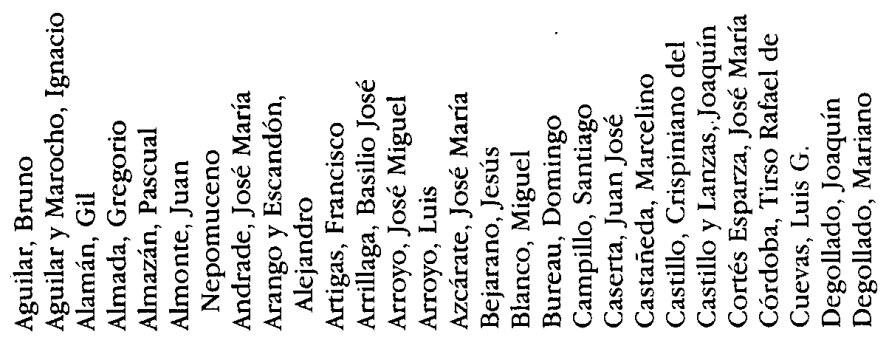




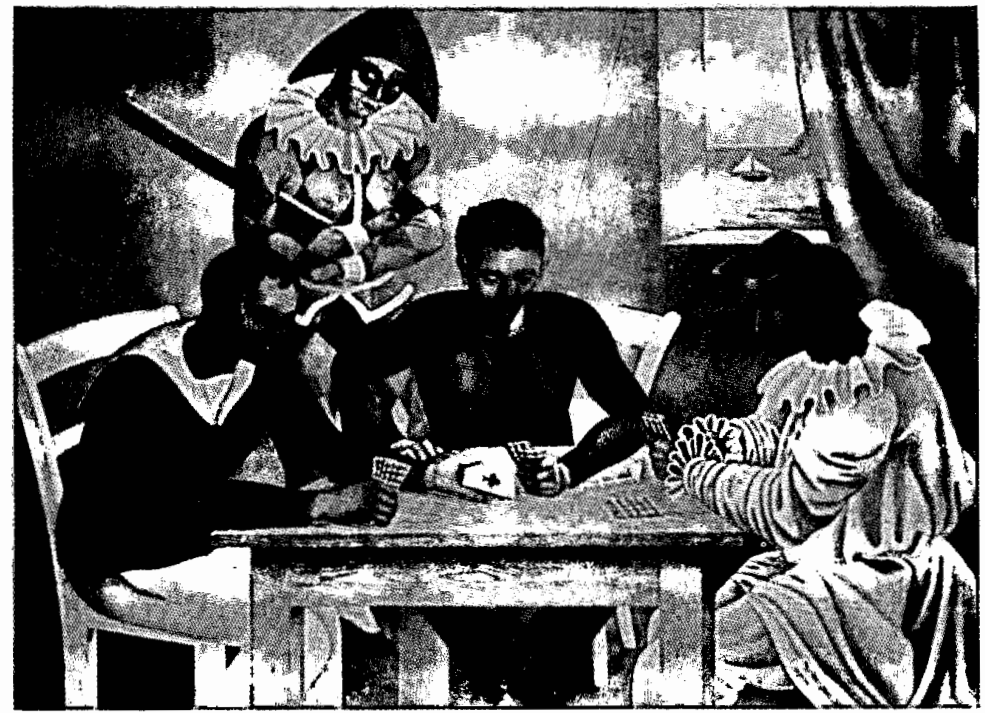

\section{ARCHIVOS}

Benson, UT-Austin Nettie Lee Benson Latin American Library, Universidad de Texas, Austin.

CONDUMEX

Centro de Estudios de Historia de México, CONDUMEX.

\section{HEMEROGRAFÍA}

-El Diario del Imperio.

-La Sociedad, Periódico Político y Literario.

\section{BIBLIOGRAFÍA}

-Adame, Jorge, "El derecho natural de Clemente de Jesús Munguía" en Soberanes, Memoria, 1983, pp. 11-25.

-Aguilar y Marocho, Ignacio, La familia enferma, Editorial Jus, México, 1969.

-Arenal, Jaime del, "Los estudios de derecho en el seminario tridentino de Morelia" en Soberanes, Memoria, 1983, pp. 27 59.

-Arrangóiz, Francisco de Paula, México desde 1808 hasta 1867, Editorial Porrúa, México, 1968.

-Boletín de las leyes del imperio mexicano, o sea código de la restauración. Colección completa de leyes y demás disposiciones dictadas por la intervención francesa, por el supremo poder ejecutivo provisional y por el imperio mexicano, con un apéndice de los documentos oficiales notables de la época, publicados por José Sebastián Segura, Imprenta Literaria, México, 1863-1865, 4 vols.

-Bulnes, Francisco, El verdadero Juárez y la verdad sobre la intervención y el imperio, Editora Nacional, México, 1973. 
-Diccionario universal de bistoria $y$ geografía. Obra dada a luz en España por una sociedad de literatos distinguidos, $y$ refundida y aumentada para su publicación en México con noticias bistóricas, geográficas, estadisticas y biográficas sobre las Américas en general y especialmente sobre México, Librería de Andrade, México, 1853-1855, 7 tomos más apéndice.

-Documentos de la época. 1840-1850, Secretaría de la Reforma Agraria, México, 1981.

-Fowler, Will, "El pensamiento político de los santanistas, 1821-1855", ponencia presentada en el congreso de homenaje a Josefina Z. Vázquez, El Colegio de México, del 11 al 13 de marzo de 1997, mecanuscrito cortesía del autor.

-González y González, Luis, La ronda de las generaciones, Secretaría de Educación Pública, México, 1984.

-González Navarro, Moisés, Anatomia del poder en México (1848-1853), El Colegio de México, México, 1977.

-Hale, Charles A., "La guerra con los Estados Unidos y la crisis del pensamiento mexicano", Secuencia, núm. 16, eneroabril de 1990, pp. 43-61.

-Lempérière, Annick, "La formación de elites liberales en el siglo XIX: el Instituto de Ciencias y Artes del estado de Oaxaca", Secuencia, núm. 30, septiembre-diciembre de 1994, pp. 57-93.

-El libro secreto de Maximiliano, Universidad Nacional Autónoma de México, México, 1963.

-Lira, Andrés, "El contencioso administrativo y el poder judicial en México a mediados del siglo XIX" en Soberanes, $\mathrm{Me}$ moria, 1983, pp. 621-634.

-Muñoz Fernández, Ángel, Los mucbachos de Letrán. José Maria Lacunza, Factoría Editores, México, 1997.

-Noriega, Cecilia, El constituyente de 1842, Universidad Nacional Autónoma de México, México, 1986. los congresos mexicanos, 1810 y 1857. Notas para su estudio" en Rojas, Poder, 1994, pp. 120-158.

-O'Gorman, Edmundo, México. El trauma de su bistoria, Universidad Nacional Autónoma de México, México, 1977.

-Pani, Erika, "Una ventana sobre la sociedad decimonónica: los periódicos católicos, 1845-1857", Secuencia, núm. 36, septiembre-diciembre de 1996, pp. 67-88.

-Ramírez, Santiago, Biografía del señor Joaquín Velázquez de León, escrita por..., Oficina Tipográfica de la Secretaría de Fomento, México, 1885.

-Ríos Zúñiga, Rosalina, "La secularización de la enseñanza en Zacatecas. Del Colegio de San Luis Gonzaga al Instituto Literario (1784-1838)", Historia Mexicana, vol. XuIv, núm. 2, octubre-diciembre de 1994, pp. 299-332.

Rojas, Beatriz, El poder y el dinero. Grupos y regiones mexicanos en el siglo $X I X$, Instituto de Investigaciones Dr. José María Luis Mora, México, 1994.

-Sierra, Justo, Juárez: su obra y su tiempo, Editorial Porrúa, México, 1970.

-Sinkin, Richard N., The mexican reform. 1855-1876. A study in liberal nation-building, University of Texas Press, Austin, 1979.

-Soberanes, José Luis (coord.), Memoria del II Congreso de bistoria del derecbo en México, Universidad Nacional Autónoma de México, México, 1983.

-Stephenson, Donald F., Origins of instability in early republican Mexico, Duke Universtity Press, Durham, N. C., 1991.

-Tena Ramírez, Felipe, Leyes fundamentales de México. 1808-1957, Editorial Porrúa, México, 1957.

-Villalpando, José, Maximiliano frente a sus jueces, Escuela Libre de Derecho, México, 1997. 